\title{
Advanced treatment in basal cell carcinoma of skin
}

\author{
Pankaj Kumar Gupta, Xuefeng Wan*, Hari Krishna Kanduri, Kurelli Sai Charan Goud, \\ Paride Abliz, Akebaier Sulaiman
}

Department of Dermatology, The first Affiliated Hospital of Xinjiang Medical University, Urumqi, P.R. China

Received: 10 December 2018

Revised: 26 December 2018

Accepted: 27 December 2018

\author{
*Correspondence: \\ Dr. Xuefeng Wan, \\ E-mail: xjwanxuefeng@ sina.com
}

Copyright: (C) the author(s), publisher and licensee Medip Academy. This is an open-access article distributed under the terms of the Creative Commons Attribution Non-Commercial License, which permits unrestricted non-commercial use, distribution, and reproduction in any medium, provided the original work is properly cited.

\begin{abstract}
In the past ten years, the occurrence of basal cell carcinoma (BCC) has amplified manifold. There are many treatment procedures to cure BCC, which includes micrographic surgery by means of surgical margins of $3-5 \mathrm{~mm}$ based on size of tumor, intrusion and location. The normally used method for treatment of basal cell carcinoma is excision by surgery. The most commonly used advanced method of excision in the treatment of bcc is Mohs' micrographic surgery (MMS). There is no proper guideline, which mentions surgery as the treatment of choice as there are no controlled randomized studies matching surgery with nonsurgical treatment options in BCC. Excision is a competent and meticulous technique as there is a low recurrence of tumor following the histological examination of tumor margins.
\end{abstract}

Keywords: Basal cell carcinoma, Moh’s micrographic surgery, Tumor margins

\section{INTRODUCTION}

BCC is the most common malignant disease affecting predominantly fair-skinned people. It is the most common cancer in Caucasians, arising in one of every five to six people in a lifetime, and the rate of occurrence is still rising every year. ${ }^{1-3}$ For treatment of BCC multiple modalities can be used, with surgical excision being most frequently used. ${ }^{4,5}$ With respect to diagnosis and treatment, in recent years there has been various advancements. In BCC there is local destruction of epithelial tissue due to neoplasm with basaloid distinction. Worldwide, it is the most common skin tumor accounting for $80 \%$ of non-melanoma skin cancers. A slowly growing tumor, BCC usually develops over the course of years occurring at an average age of 60 , though younger individuals ( $<40$ years) have been increasingly affected. According to the WHO, basal cell carcinoma can be classified into the following subtypes:
- Superficial basal cell carcinoma,

- Nodular (solid) basal cell carcinoma,

- Micronodular basal cell carcinoma,

- Infiltrative basal cell carcinoma,

- Fibroepithelial basal cell carcinoma (Pinkus tumor),

- Basal cell carcinoma with adnexal differentiation,

- Basosquamous carcinoma,

- Keratotic basal cell carcinoma

There are many varieties of treatment options available for curing basal cell skin cancers. The options hinge on elements like the tumor dimensions and position, age of patient, general health, and preferences. If not treated, cancer can spread to the surrounding tissues but very rarely, it can metastasize. Majority of the effective treatment preferences are discussed in this article. After Mohs surgery the chance of recurrence is less than $5 \%$ when compared to other methods of treatments, which have recurrence ranges up to $15 \%$. However, the chance 
of recurrence is based on the size of the tumor. Large tumors tend to recur more often than small tumors, but they can be cured successfully.

\section{DISCUSSION}

The treatment of BCC is only achieved by complete resection. Topical agents can be used for superficial BCC whereas options of Radiation therapy and/or systemic therapy is available for locally advanced or metastatic disease. ${ }^{6,7}$ The objective of treatment for BCC as stated by National Comprehensive Cancer Network (NCCN), is the eradication of the tumor with maximal conservation of function and physical form. ${ }^{8}$ As such, treatment option should depend on the patient's specific risk factors and inclinations. ${ }^{8}$

\section{Surgical treatment}

Surgical treatment of BCC aims at eliminating the tumor and hindering further proliferation of malignancy histologic subtype of BCC, the location and size of tumors, age of the patient, patient's ability to tolerate surgery, and the expense are factors that determine the plan of therapy. Primary lesions are less aggressive when compared to the recurrent tumor, and subclinical extension showed to be elevated. Tumors that are best treated with methods that permit inspection of the tissue margins are those occurring near important or cosmetically delicate structures and those, which are destructive. Mohs micrographic surgery, Curettage, and removal with margin examination are the most frequently used operating procedures of treating BCC. Radiotherapy is an additional treatment option available at disposal along with cryotherapy, which is seldom used. Recurrence after irradiation makes operation compulsory.

\section{a) Curettage and electrodesiccation $(C \& E)$}

$\mathrm{C} \& \mathrm{E}$ is the process of alternatively scraping away tumor tissue with a curette down to a firm layer of the normal dermis and denaturing the area by electrodesiccation needing about three cycles in a session. C\&E does not allow histologic margin evaluation but it is a fast and unexpansive method for superficial lesions. Overall 5year cure rates of $91 \%$ to $97 \%$ have been reported in patients with $\mathrm{BCC}$ selected for $\mathrm{C} \& \mathrm{E}$ in various observational and retrospective studies. ${ }^{9,10}$ However, some studies have reported higher recurrence rates $(19 \%$ $27 \%$ ), possibly due to high-risk locations (21\%) and histologic subtypes $(27 \%) .^{6,11-13}$ The outcome is highly dependent on the skill set of the operating surgeon and optimal cure rates are seen in instances with experienced practitioners. ${ }^{14}$ These methods are considered effective for accurately selected 3 caveats with low-risk tumors. ${ }^{13}$ First, the regions with terminal hair growth must be excluded in this type of treatment like axillary regions, pubic, scalp, or scalp or beard part in males because there is a risk of the tumor spreading into the follicular structures that may not be effectively removed. Second, if the subcutaneous level is reached during the course of surgery, surgical excision should generally be performed instead. This change in therapy is necessary because the effectiveness of the C\&E technique rests on the ability of the clinician to distinguish between the firm, normal dermis and soft tumor tissue when using a sharp curette. Since tumor tissue is harder than subcutaneous adipose tissue, the capability of the cure rate to differentiate and, consequently, to totally excised tumor cells, vanishes. Thirdly, based only on the presence of a low-risk tumor curettage has been done, biopsy results of the tissue taken at the time of curettage should be reviewed to confirm that there are no high-risk pathologic features that would require additional therapy.

\section{b) Mohs micrographic surgery or excision}

The American Academy of Dermatology collaborated with American Society for Mohs Surgery, the American Society for Dermatologic Surgery Association and the American College of Mohs Surgery to develop the criteria for selection of Mohs micrographic surgery in 69 BCC scenarios. ${ }^{15}$

\section{Indications:}

- Tumors arising at sites known to have a high treatment failure rate with conventional methods

- Tumors with poorly demarcated clinical margins

- Tumors which are greater than $1 \mathrm{~cm}$ in diameter and present anywhere on the face

- Tumors which are greater than $2 \mathrm{~cm}$ in diameter

- Tumors with infiltrative or morpheaform/sclerotic histopathologic patterns

- Tumors arising in sections where extreme conservation of uncomplicated tissue is required, as is a good cosmetic result (including, but not restricted to, the eyelids, nose, ears, lips)

In Mohs surgery, the clinically apparent tumor and a thin border of normal skin surrounding the abnormality is removed. ${ }^{16,17}$ The tissue surrounding the tumor or the margin adjacent to the tumor have a saucer-shaped tissue specimen and is divided and marked so that the total of the undersurface and outer boundaries of the tumor are examined microscopically to minimize sampling error. Use of the frozen-section technique allows for an examination of tissue while the patient is in the office. Further excision is performed only on those parts of the tissue, which are microscopically charted so that there is no additional tumor spread.

Excision or removal by curettage is often used for clinically apparent tumor after administering sufficient anesthesia to the patient. ${ }^{18}$ Usually less than $1 \mathrm{~mm}$ thickness of tissue (stage) is collected from the surrounding epidermis/ dermis /subcutis, which is then examined under the microscope. 
Processing tissue allows for localization of any tumor that might persist, which enables the surgeon to take additional stages (pieces or sections) from the site. Mohs micrographic surgery is considered a criterion standard of care for BCC treatment, as it is associated with the lowest recurrence rate. ${ }^{19}$ Invasive $\mathrm{BCC}$ also can be treated with Mohs surgery to clear peripheral margins with deeper penetration that have been treated surgically by other disciplines. $^{20}$

Best cure rates (primary BCC- 99\%, recurrent BCC- 9095\%) and best long-term cure rates among all available BCC treatments were reported with Mohs micrographically controlled surgery. It spares as much normal skin tissue as possible. It is the primary treatment option considered for micronodular, morpheaform, recurrent and infiltrating types of BCC. This allows examining almost $100 \%$ of tissue, compared to standard vertical sectioning (bread-loaf), which examines $<1 \%$ of outer margins. Mohs micrographic surgery collects relatively thin layers of tissue only in areas of proven tumor, making this procedure a tissue-sparing technique. Usually, excision of tumor and repair can be accomplished on the same day. In an analysis, 5-year recurrence rates for cured $\mathrm{BCC}$ following Mohs micrographic surgery was significantly lower(1\%) compared to other treatment modalities (cryosurgery$7.5 \%$, C\&E-7.7\%, radiotherapy-8.7\%, and surgical excision-10.1\%). ${ }^{21}$ In yet another study, Malhotra et al reported a significantly lower 5-year recurrence rate for primary tumors $(0 \%)$ and recurring tumors $(7.8 \%)$ after Mohs microsurgery. ${ }^{22}$

Mohs surgery is an expensive, time-consuming procedure compared with curettage and carry the risk of infection. ${ }^{23}$ However, savings on treating fewer recurrences should be factored in, when deciding against the procedure on the economical basis ${ }^{21}$. Factors such as $32-39 \%$ of cases of non-melanoma skin cancer require a second excision to obtain clear margins with standard surgical excision also favor moh's surgery

\section{c) Cryosurgery}

Cryosurgery is a fast and economical option of destroying tumor cells of $\mathrm{BCC}$ by freeze-thaw cycles. In primary $\mathrm{BCC}$, recurrence rates for cryosurgery range between $0 \%-13 \%$, and mean recurrence rates range between $3-4 \%$ respectively from Systematic reviews of historical data and pooled analyses. ${ }^{9,11}$ Prospective trials on cryosurgery in $\mathrm{BCC}$ reported $\mathrm{BCC}$ recurrence rates ranging between $5 \%$ to $39 \% .^{23,24}$ Factors such as patient selection, variable follow-up durations, and differences in technique and operator skill might be responsible for the variability in reported recurrence rates. A retrospective review of 415 BCCs treated by a single clinician reported the lowest recurrence rate (5-year cure rate of $99 \%) .{ }^{25}$ However, prospective randomized trials comparing cryosurgery with other treatment modalities of BCC concluded that cryotherapy yielded in poorer cosmetic outcomes. ${ }^{24-26}$

\section{Radiotherapy}

Radiotherapy, with promising cure rates of $90 \%$ for BCC usually require exposing the tumor to $\mathrm{x}$-ray beams through the skin, without the need for incision or anesthesia, Depending on the tumor characteristics total destruction of tumor cells requires treatment spanning a few weeks/sometimes daily over a month. Indications for radiation include surgically unresectable tumors, elderly and patients in ill health. Although adjacent tissue is spared, it carries radiation risks and long-term cosmetic problems.

\section{Photodynamic therapy (PDT)}

PDT involves irradiating high energy blue light over the lesion after topical application of a light-sensitizing agent(5-aminolevulinic acid), leading to selective destruction of BCCs in the presence of oxygen with minimal damage to surrounding normal tissue. It carries cure rates ranging between $70 \%$ to $90 \%$ and FDAapproved treatment modality of superficial or nodular BCC. It can sometimes result in redness, pain, and swelling at the site of treatment. Patients must be advised strictly against exposure to sunlight or UV light for at least a duration of 48 hours, as it may cause severe sunburn due to further activation of light sensitizing agent.

The photosensitizer releases energy while returning to ground state from the excited state it attained by exposure of the light beam of specific wavelengths. This energy released is responsible for selective cell killing. ${ }^{27}$ PDT has less chance of causing mutation, or carcinogenesis. ${ }^{28}$ The types and routes of administration of photosensitizers available vary. Aminolevulinic acid (ALA) and methyl aminolevulinate (MAL) are precursors that require conversion to photo-activable porphyrin and the only photo-sensitizers approved for dermatologic indications. ${ }^{29}$ ALA crosses cell membrane, and converts to protoporphyrin IX (PpIX) inside the cell, while ALAesters, like MAL, needs to be first hydrolyzed to ALA in the cytosol. ${ }^{30}$ Additional factors such as temperature affect the efficiency of PpIX production and facilitate conversion. ${ }^{31}$ ALA is less lipid soluble compared to MAL due to which the former has less penetration through the skin ( $<2 \mathrm{~mm}$ skin depth) or cell membranes, restricting its clinical application to superficial lesions. ${ }^{32}$ MAL has increased lipophilicity with deeper penetration through skin compared to ALA. ${ }^{33}$ Vitamin D as a potential adjuvant treatment enhanced ALA-induced PpIX synthesis in in-vivo and ex-vivo imaging, resulting in increased tumor cell death after PDT treatment. ${ }^{34}$

\section{Laser therapy}

Laser therapy involves targeting a beam of light of a specific wavelength at the BCC to destroy superficial lesion. Depending on the type of lasers, ablative lasers vaporize the tumors and nonablative lasers produce heat 
at the site of lesion destroying the tumor. Laser treatment has recurrence rates similar to PDT and is used as the secondary choice of therapy when other modalities yield dismal results. It is yet to be approved to be considered a therapeutic option for BCC.

\section{Vascular lasers}

Efficacy of vascular targeting lasers in the treatment of BCC has been demonstrated in several studies. ${ }^{35-37} \mathrm{~A}$ pilot study with 12 patients investigated the treatment of BCC with only $595 \mathrm{~nm}$ pulsed dye laser (PDL) with 4 sessions over a period of 2 weeks. ${ }^{36}$ Response rates to vascular lasers were determined by the level of histological evidence of clearance: histological evidence involves collecting a $4 \mathrm{~mm}$ margin surgically as a disk excision after a minimum of 2 weeks following the final laser treatment and analyzing it histo-pathologically. Response rates to PDL were dependent on tumor size and histologic subtypes. Tumors of small diameter $(<1.5 \mathrm{~cm})$ showed better response rates compared to tumours of larger diameter $(>1.5 \mathrm{~cm}) .{ }^{36}$ Superficial, nodular, micronodular, and "keratinizing" histological types of BCC demonstrated a complete response. In the patients with larger tumor diameter who responded to PDL, there was around $71 \%$ to $99 \%$ reduction in tumor size. Among the subtypes of BCC, superficial subtype demonstrated a complete response to PDL more frequently. Clinical side effects of PDL includes purpura and gray discoloration of the skin in few subjects with the ensuing formation of hemorrhagic scale crust. The effectiveness of PDL has been seen clinically with complete healing in 2 weeks. ${ }^{36}$

In another study on 29 patients within total 39 biopsyproven diagnoses of $\mathrm{BCC}$ on the face, received 3 treatments on average with $595 \mathrm{~nm}$ PDL at 2-4 week intervals. ${ }^{39}$ In the study complete clinical rectification was $75 \%$ of treated facial BCCs where mean follow-up time was 11 months, recurrence was reported in $16 \%$ of tumors, and $9 \%$ had incomplete rectification after completion of 4 treatments. Recurrence is common in nodular, infiltrative, or mixed types of facial BCC. Erythema, mild edema and dusky purpura are the commonly reported side effects which usually subsided in 1 week. ${ }^{38}$ Cosmetic results with PDL on facial BCC were satisfactory as there was no scarring reported in these cases. $^{38}$

Although the above-mentioned studies show promise ineffectiveness, it has to be taken into consideration of the settings and based on theorized vascular selectivity the settings may surpass the threshold, particularly under high fluences without epidermal cooling. However, PDL treatments yield cosmetically pleasing outcomes when compared to electrodessication and curettage. Moreover, the follow-up duration in the above studies may not pick up all recurrence. ${ }^{39,40}$ A follow-up of 5 or more years, might be better at recording the true potential recurrence. ${ }^{10,39,40}$

\section{Ablative lasers}

Ablative lasers have wavelengths that fall within the infrared spectrum. Carbon dioxide $\left(\mathrm{CO}_{2}\right)(10,600 \mathrm{~nm})$ and erbium yttrium aluminum garnet (Er:YAG) lasers $(2,940$ $\mathrm{nm}$ ) are clinically used lasers which ablate tissue by vaporizing water in tissue. Precise control of tissue vaporization is achieved by delivering high fluences with short duration of the pulse, minimizing nonspecific "spillover" thermal damage to tissue outside the treatment area. The old ablative lasers used continuous wave $(\mathrm{CW})$ mechanism of action, which is a continuous light beam with minimal variability in power output over time. This resulted in nonselective thermal injury causing unintended damage to tissue outside the treatment area. With advancement in technology, more controlled quasicontinuous mode (QSM) and pulsed lasers were developed, largely replacing $\mathrm{CW}$ models. The QSM models are basically $\mathrm{CW}$ lasers that are mechanically engineered to deliver pulses.

The depth of tissue ablation per pass is superficial for Co2 lasers (in $20 \mathrm{~mm}$ range). ${ }^{41,42}$ Distances are crucial to reaching adequate fluence for the tissue to be precisely ablated due to vaporization of water in tissue. Radiation of heat and decrease in fluence causes tissue to coagulate instead of vaporization of water, which provides hemostasis and stimulation of collagen synthesis. The depth of tissue ablation per pass for Er:YAG lasers are less (in $2 \mathrm{~mm}$ range) for a single pulse, even though multiple pulses can be delivered. Er:YAG laser has around 15 times greater affinity to water than $\mathrm{CO}_{2}$ laser, this character of Er:YAG laser allows for higher tissue vaporization but limiting the coagulation. Due to this the hemostasis and collagen stimulation, may be reduced with Er:YAG compared to $\mathrm{CO}_{2}$ lasers.

Clinical efficacy of $\mathrm{CO}_{2}$ laser treatment of $\mathrm{BCC}$ was studied by a prospective investigatory trial with 140 patients, reporting a $100 \%$ cure rate and $0 \%$ recurrence after 3 years follow-up. ${ }^{43}$ In the study, the patients with single or multiple superficial or nodular subtypes of BCCs $<1.5 \mathrm{~cm}$ in diameter were treated with a superpulsed $\mathrm{CO}_{2}$ laser at 1 to $3 \mathrm{~mm}$ spot size, 2 to 3 milliseconds pulse duration, and $10 \mathrm{~Hz}$ frequency. ${ }^{43}$ Intraoperative histopathology with an average of 3 scrape biopsies was collected from each patient to assess the efficacy of treatment. The timing of biopsy sample collection was, $1^{\text {st }}$ sample before laser vaporization, $2^{\text {nd }}$ sample after the first pass, and $3^{\text {rd }}$ sample after the second pass immediately after reaching "deep dermis". All the final samples were cytologically "clear". 43 Authors reported $7-10$ days of average healing time, with "good aesthetic outcomes" in all the cases, although no details on cosmetic outcome were provided. The authors reported no recurrence by clinical examination at the end of the 3-year follow-up; although, the final follow-up lacked documented histologic confirmation. ${ }^{43}$ 
Ablative $\mathrm{CO}_{2}$ lasers provide reliable and effective outcomes both oncologic and cosmetic with decreased complications like bleeding, infections, scarring, and alleviation of morbidity. Further research is required into BCC treatments with Er:YAG laser as many of the studies which demonstrated cure rates $>90 \%$, combined multiple "stages" of laser passes and intraoperative histopathological evaluation with confirmation of tumor eradication. This technique can notably increase the chances of complete resolution while diminishing the possibility of recurrence. Ablative laser treatments, with/without intraoperative histopathologic evaluation in $\mathrm{BCC}$ is yet to demonstrate benefit in tumor control rates over currently available standard treatment options. Although the cosmetic outcomes with Ablative laser treatments are pleasing, no comparison studies have been undertaken to confirm this till date. Cosmetic outcomes are also dependant on the size, location, and particularly the treated tumor depth. Further randomized, controlled and side-by-side comparison studies are to be undertaken to compare ablative laser therapy with current standard treatments and inclusion criteria such as longer follow-up durations to study the recurrence rates.

\section{Topical agents}

Application of topical agents in the form of gel/cream/solutions to treat BCC has been limited to small and specific subtypes of the tumor.

Imiquimod is a FDA-approved immune system stimulant with clinical application limited to only superficial BCC and cure rates between $80 \%$ and $90 \%$, which gentle application of cream into the tumor 5 times a week for 6 weeks or longer. It acts by stimulating the body to produce a chemical called interferon, which attacks cancer.

5-Fluorouracil (5-FU) has been FDA-approved for treating superficial $\mathrm{BCC}$, with comparable cure rates to imiquimod. It (cream/liquid form of drug) is gently applied into the tumor 2times a day for 3-6 weeks duration. Side effects are inconsistent; some patients usually experience inflammation, redness, and irritation.

No histopathologic evaluation is undertaken in C\&E, radiotherapy, topical medications and cryosurgery, which is a significant drawback (unlike surgical treatment options). Hence, it cannot be established with confirmation to what extent removal of the tumor is undertaken.

\section{Oral medication}

In 2012, Vismodegib has been approved by FDA as an oral medication to treat very rare cases of locally advanced BCC that became life-threatening or metastatic BCC. It works as a hedgehog signaling pathway inhibitor (HSPI). It is approved only for instances where the tumor's nature forbids treatments such as radiotherapy/surgery. Sonidegib is another oral hedgehog inhibitor drug used for locally advanced BCC, particularly in cases where tumors recurred after radiotherapy/surgery, or in patients not suitable for radiotherapy/surgery. Sonidegib and Vismodegib cause death or birth defects in embryo/fetus when used in a pregnant woman or females in the reproductive age group. Both male and female patients in the reproductive age group should be warned of the risk of birth defects and the need for effective contraception should be advised. Potential side effects (other than birth defects in the fetus) include severe musculoskeletal problems, raised levels of serum creatine kinase, spasms and muscle pain.

\section{Management of locally advanced and metastatic basal cell carcinoma}

Untreated BCC may become locally destructive up to an extent that option of surgical resection is not viable due to its large size or proximity to functionally vital structures. In such cases, radiotherapy may be unproductive. Until recently, options for treatment of this locally advanced BCC are limited. Cases of BCC metastasis are extremely rare (approximately $0.003 \%-0.1 \%$ of cases). ${ }^{44}$ The approval of Vismodegib for treating locally advanced BCC and metastatic BCC was based on phase II clinical trial (ERIVANCE) results, which elicited good outcomes in cases of metastatic BCC (30\%) and locally advanced BCC cases $(43 \%)$ with a median response duration of 7.6 months in both cohorts. ${ }^{45}$ Adverse events such as alopecia, muscle spasms, weight loss, taste disturbance and fatigue were common. An expanded access study corroborated the efficacy of Vismodegib in treating cases of locally advanced BCC (46.4\%) and metastatic BCC $(30.8 \%)$ with objective responses. ${ }^{46} \mathrm{~A}$ randomized, double blind, placebo-controlled trial concluded that Vismodegib reduces BCC tumor burden and inhibits the growth of new BCCs in patients with NBCCS. ${ }^{47}$ Due to successful outcomes with Vismodegib and similar molecules in both pre-clinical and clinical studies, topical formulations of HSPI's are being investigated for treating BCC. ${ }^{48,49}$ Vismodegib is the $1^{\text {st }}$ potent medical treatment for advanced BCC; yet, several challenges need to be addressed such as understanding the genetic foundation for clinical response and devising strategies to overcome acquired resistance.

\section{CONCLUSION}

Surgical techniques are considered the gold standard of BCC treatment according to available data, with Mohs micrographic surgery is used in high-risk lesions. Appropriately selected patients with primary low-risk lesions may benefit from alternative treatments such as PDT, cryotherapy. Radiotherapy should be considered for treating surgically unresectable tumors, in elderly and ill patients. Promising results were obtained with HSPI's like Vismodegib, Sonidegib in the management of advanced BCC. Factors such as optimal treatment length, recurrence risk and drug resistance of HSPI's have to be studied further, while, side effects remain to be a major 
concern. Insufficient evidence on topical agents limits the possibility of recommending these drugs in clinical use. Continued research on the efficacy of available treatments is required with studies focusing on diverse factors such as histologic ascertainment of cure, longterm follow-up, tumor subtype based stratification, and comparison of outcomes of alternative treatment modalities with surgical outcomes.

Funding: No funding sources

Conflict of interest: None declared

Ethical approval: Not required

\section{REFERENCES}

1. Marghoob AA. Basal and squamous cell carcinomas. What every primary care physician should know. Postgraduate Med. 1997;102(2):13942, 146, 152-4 passim.

2. Rigel DS, Friedman RJ, Kopf AW. Lifetime risk for development of skin cancer in the U.S. population: current estimate is now 1 in 5. Journal of the American Acad Dermatol. 1996;35(6):1012-3.

3. Holme SA, Malinovszky K, Roberts DL. Changing trends in non-melanoma skin cancer in South Wales, 1988-98. Br J Dermatol. 2000;143(6):12249.

4. Kuijpers DI, Thissen MR, Neumann MH. Basal cell carcinoma: treatment options and prognosis, a scientific approach to a common malignancy. Am J Clin Dermatol. 2002;3(4):247-59.

5. Bower CP, Lear JT, de Berker DA. Basal cell carcinoma follow-up practices by dermatologists: a national survey. Br J Dermatol. 2001;145(6):94956.

6. Julian C, Bowers PW, Pritchard C. A comparative study of the effects of disposable and Volkmann spoon curettes in the treatment of basal cell carcinoma. The Br J Dermatol. 2009;161(6):1407-9.

7. Connolly SM, Baker DR, Coldiron BM, Fazio MJ, Storrs PA, Vidimos AT, et al. AAD/ACMS/ASDSA/ASMS 2012 appropriate use criteria for Mohs micrographic surgery: a report of the American Academy of Dermatology, American College of Mohs Surgery, American Society for Dermatologic Surgery Association, and the American Society for Mohs Surgery. Dermatologic surgery : official publication for American Society for Dermatologic Surgery [et al]. 2012;38(10):1582603.

8. Miller SJ. The National Comprehensive Cancer Network (NCCN) guidelines of care for nonmelanoma skin cancers. Dermatologic surgery : official publication for American Society for Dermatologic Surg. 2000;26(3):289-92.

9. Rowe DE, Carroll RJ, Day CL, Jr. Long-term recurrence rates in previously untreated (primary) basal cell carcinoma: implications for patient follow-up. J Dermatol Surg Oncol. 1989;15(3):31528.

10. Barlow JO, Zalla MJ, Kyle A, DiCaudo DJ, Lim KK, Yiannias JA. Treatment of basal cell carcinoma with curettage alone. J Am Acad Dermatol. 2006;54(6):1039-45.

11. Thissen MR, Neumann MH, Schouten LJ. A systematic review of treatment modalities for primary basal cell carcinomas. Arch Dermatol. 1999;135(10):1177-83.

12. Blixt E, Nelsen D, Stratman E. Recurrence rates of aggressive histologic types of basal cell carcinoma after treatment with electrodesiccation and curettage alone. Dermatologic surgery: official publication for Am Society Dermatologic Surg. 2013;39(5):719-25.

13. Rodriguez-Vigil T, Vazquez-Lopez F, Perez-Oliva $\mathrm{N}$. Recurrence rates of primary basal cell carcinoma in facial risk areas treated with curettage and electrodesiccation. J Am Acad Dermatol. 2007;56(1):91-5.

14. Kopf AW, Bart RS, Schrager D, Lazar M, Popkin GL. Curettage-electrodesiccation treatment of basal cell carcinomas. Arch Dermatol. 1977;113(4):43943.

15. Connolly SM, Baker DR, Coldiron BM, Fazio MJ, Storrs PA, Vidimos AT, et al. AAD/ACMS/ASDSA/ASMS 2012 appropriate use criteria for Mohs micrographic surgery: a report of the American Academy of Dermatology, American College of Mohs Surgery, American Society for Dermatologic Surgery Association, and the American Society for Mohs Surgery. J Am Acad Dermatol. 2012;67(4):531-50.

16. Bennett RG. Current concepts in Mohs micrographic surgery. Dermatologic clinics. 1991;9(4):777-88.

17. Roenigk RK. Mohs' micrographic surgery. Mayo Clinic proceedings. 1988;63(2):175-83.

18. Lawrence CM. Mohs' micrographic surgery for basal cell carcinoma. Clinical and experimental dermatology. 1999;24(2):130-3.

19. Smeets NW, Krekels GA, Ostertag JU, Essers BA, Dirksen CD, Nieman FH, et al. Surgical excision vs Mohs' micrographic surgery for basal-cell carcinoma of the face: randomised controlled trial. Lancet (London, England). 2004;364(9447):176672.

20. Ducic Y, Marra DE, Kennard C. Initial Mohs surgery followed by planned surgical resection of massive cutaneous carcinomas of the head and neck. The Laryngoscope. 2009;119(4):774-7.

21. Tierney EP, Hanke CW. Cost effectiveness of Mohs micrographic surgery: review of the literature. J Drugs Dermatol: JDD. 2009;8(10):914-22.

22. Malhotra R, Huilgol SC, Huynh NT, Selva D. The Australian Mohs database, part II: periocular basal cell carcinoma outcome at 5-year follow-up. Ophthalmology. 2004;111(4):631-6.

23. Basset-Seguin N, Ibbotson SH, Emtestam L, Tarstedt M, Morton C, Maroti M, et al. Topical methyl aminolaevulinate photodynamic therapy versus cryotherapy for superficial basal cell carcinoma: a 5 year randomized trial. European J Dermatol: EJD. 2008;18(5):547-53.

24. Hall VL, Leppard BJ, McGill J, Kesseler ME, White JE, Goodwin P. Treatment of basal-cell 
carcinoma: comparison of radiotherapy and cryotherapy. Clin Radiol. 1986;37(1):33-4.

25. Kuflik EG. Cryosurgery for skin cancer: 30 -year experience and cure rates. Dermatologic surgery : official publication for American Society for Dermatologic Surg [et al]. 2004;30(2):297-300.

26. Wang I, Bendsoe N, Klinteberg CA, Enejder AM, Andersson-Engels S, Svanberg $\mathrm{S}$, et al. Photodynamic therapy vs. cryosurgery of basal cell carcinomas: results of a phase III clinical trial. The Br J Dermatol. 2001;144(4):832-40.

27. Dolmans DE, Fukumura D, Jain RK. Photodynamic therapy for cancer. Nature Rev Cancer. 2003;3(5):380-7.

28. Mroz P, Yaroslavsky A, Kharkwal GB, Hamblin MR. Cell death pathways in photodynamic therapy of cancer. Cancers. 2011;3(2):2516-39.

29. Angell-Petersen E, Sorensen R, Warloe T, Soler AM, Moan J, Peng Q, et al. Porphyrin formation in actinic keratosis and basal cell carcinoma after topical application of methyl 5-aminolevulinate. The J Investigative Dermatol. 2006;126(2):265-71.

30. Matei C, Tampa M, Poteca T, Panea-Paunica G, Georgescu SR, Ion RM, et al. Photodynamic therapy in the treatment of basal cell carcinoma. J Med Life. 2013;6(1):50-4.

31. Gerritsen MJ, Smits T, Kleinpenning MM, van de Kerkhof PC, van Erp PE. Pretreatment to enhance protoporphyrin IX accumulation in photodynamic therapy. Dermatology (Basel, Switzerland). 2009;218(3):193-202.

32. Di Venosa G, Hermida L, Batlle A, Fukuda H, Defain MV, Mamone L, et al. Characterisation of liposomes containing aminolevulinic acid and derived esters. J Photochem Photobiol Biol. 2008;92(1):1-9.

33. Kuijpers DI, Thissen MR, Thissen CA, Neumann MH. Similar effectiveness of methyl aminolevulinate and 5-aminolevulinate in topical photodynamic therapy for nodular basal cell carcinoma. J Drugs Dermatol. 2006;5(7):642-5.

34. Rollakanti K, Anand S, Maytin EV. Topical calcitriol prior to photodynamic therapy enhances treatment efficacy in non-melanoma skin cancer mouse models. Proceedings of SPIE--the International Society for Optical Engineering. 2015;9308:93080.

35. Jalian HR, Avram MM, Stankiewicz KJ, Shofner JD, Tannous Z. Combined $585 \mathrm{~nm}$ pulsed-dye and $1,064 \mathrm{~nm} \mathrm{Nd}$ :YAG lasers for the treatment of basal cell carcinoma. Lasers in Surg Med. 2014;46(1):1-7.

36. Shah SM, Konnikov N, Duncan LM, Tannous ZS. The effect of $595 \mathrm{~nm}$ pulsed dye laser on superficial and nodular basal cell carcinomas. Lasers Surg Med. 2009;41(6):417-22.

37. Campolmi P, Mavilia L, Bonan P, Cannarozzo G, Lotti TM. $595 \mathrm{~nm}$ pulsed dye laser for the treatment of superficial basal cell carcinoma. Lasers Med Sci. 2005;20(3-4):147-8.
38. Minars N, Blyumin-Karasik M. Treatment of Basal cell carcinomas with pulsed dye laser: a case series. J Skin Cancer. 2012;2012:286480.

39. Karia PS, Han J, Schmults CD. Cutaneous squamous cell carcinoma: estimated incidence of disease, nodal metastasis, and deaths from disease in the United States, 2012. J Am Acad Dermatol. 2013;68(6):957-66.

40. Christenson LJ, Borrowman TA, Vachon CM, Tollefson MM, Otley CC, Weaver AL, et al. Incidence of basal cell and squamous cell carcinomas in a population younger than 40 years. JAMA. 2005;294(6):681-90.

41. Omi T, Numano K. The Role of the CO2 Laser and Fractional CO2 Laser in Dermatology. Laser Therap. 2014;23(1):49-60.

42. Humphreys TR, Malhotra R, Scharf MJ, Marcus SM, Starkus L, Calegari K. Treatment of superficial basal cell carcinoma and squamous cell carcinoma in situ with a high-energy pulsed carbon dioxide laser. Arch Dermatol. 1998;134(10):1247-52.

43. Campolmi P, Brazzini B, Urso C, Ghersetich I, Mavilia L, Hercogova J, et al. Superpulsed CO2 laser treatment of basal cell carcinoma with intraoperatory histopathologic and cytologic examination. Dermatologic surgery: official publication for American Society for Dermatologic Surgery [et al]. 2002;28(10):909-11.

44. von Domarus H, Stevens PJ. Metastatic basal cell carcinoma. Report of five cases and review of 170 cases in the literature. J Am Acad Dermatol. 1984;10(6):1043-60.

45. Sekulic A, Migden MR, Oro AE, Dirix L, Lewis $\mathrm{KD}$, Hainsworth JD, et al. Efficacy and safety of vismodegib in advanced basal-cell carcinoma. The New England J Med. 2012;366(23):2171-9.

46. Chang AL, Solomon JA, Hainsworth JD, Goldberg L, McKenna E, Day BM, et al. Expanded access study of patients with advanced basal cell carcinoma treated with the Hedgehog pathway inhibitor, vismodegib. J Am Acad Dermatol. 2014;70(1):60-9.

47. Tang JY, Mackay-Wiggan JM, Aszterbaum M, Yauch RL, Lindgren J, Chang K, et al. Inhibiting the hedgehog pathway in patients with the basal-cell nevus syndrome. The New England $J$ Med. 2012;366(23):2180-8.

48. Skvara H, Kalthoff F, Meingassner JG, WolffWiniski B, Aschauer H, Kelleher JF, et al. Topical treatment of Basal cell carcinomas in nevoid Basal cell carcinoma syndrome with a smoothened inhibitor. J Investigative Dermatol. 2011;131(8):1735-44.

49. Tang T, Tang JY, Li D, Reich M, Callahan CA, Fu $\mathrm{L}$, et al. Targeting superficial or nodular Basal cell carcinoma with topically formulated small molecule inhibitor of smoothened. Clinical cancer research: an official journal of the American Association for Cancer Res. 2011;17(10):3378-87.

Cite this article as: Gupta PK, Wan X, Kanduri HK Goud KSC, Abliz P, Sulaiman A. Advanced treatment in basal cell carcinoma of skin. Int J Res Dermatol 2019;5:217-23. 